Full Length Article

\title{
Laminar flame speed of lignocellulosic biomass-derived oxygenates and blends of gasoline/oxygenates
}

\author{
Yi Wu ${ }^{\mathrm{a}, \mathrm{b}, *},{\text { Bjorn } \text { Rossow }^{\mathrm{b}} \text {, Vincent Modica }}^{\mathrm{b}}$, Xilong $\mathrm{Yu}^{\mathrm{a}, \mathrm{c}}$, Linlin $\mathrm{Wu}^{\mathrm{d}}$, Frédéric Grisch ${ }^{\mathrm{b}}$ \\ ${ }^{a}$ State Key Laboratory of High Temperature Gas Dynamics, Institute of Mechanics, Chinese Academy of Sciences, Beijing 100190, China \\ ${ }^{\mathrm{b}}$ CORIA - UMR 6614, Normandie Université, CNRS, INSA et Université de Rouen, Campus Universitaire du Madrillet, 76800 Saint-Etienne du Rouvray, France \\ ${ }^{\mathrm{c}}$ School of Engineering Science, University of Chinese Academy of Sciences, Beijing 100049, China \\ ${ }^{\mathrm{d}}$ Beijing Research Institute of Coal Chemistry, China Coal Research Institute, Beijing 100013, China
}

\section{A R T I C L E I N F O}

\section{Article history:}

Received 12 March 2017

Received in revised form 13 April 2017

Accepted 19 April 2017

Available online 25 April 2017

\section{Keywords:}

Laminar flame speed

Oxygenated fuels

Gasoline

High pressure and high temperature

\begin{abstract}
A B S T R A C T
Oxygenates present in partially hydro processed lignocellulosic-biomass pyrolysis oil to be component of second generation bio-fuels have been examined for their compact on the laminar flame speed of gasoline. Experiments were performed in an elevated pressure combustion vessel designed around a concept of a premixed Bunsen flame. Laminar flame speed measurements were firstly conducted for neat oxygenate fuel (anisole, 4-methylanisole and ethylvalerate) $/ \mathrm{N}_{2} / \mathrm{O}_{2}$ mixtures at conditions $\mathrm{T}=423 \mathrm{~K}$, $\mathrm{P}=0.1 \mathrm{MPa}$ and $\varphi=0.6-1.3$. It has been observed that anisole has a higher flame speed compared to 4methylanisole and ethylvalerate. Meanwhile, very similar values of flame speeds have been obtained for 4-mythlanisole and ethylvalerate fuels. To learn the potential effect of these oxygenates present in biofuels acting as drop-in additives on the petroleum-based gasoline fuel, a five components surrogate gasoline fuel (hexane, 2,3-dimethyl-2-butene, cyclohexane, isooctane, and toluene) was then proposed and validated by comparing its laminar flame speed with commercial gasoline. Laminar flame speeds measurements were finally performed for the blends mixed by the proposed surrogate gasoline and different percentage of oxygenates over a large working condition range including $T=400-473 \mathrm{~K}, \varphi=0.6$ 1.3 and $\mathrm{P}=0.1-0.8 \mathrm{MPa}$. The influence of studied oxygenates as additives on gasoline has been found to be negligible for values up to $10 \%(\mathrm{wt})$ which is insensitive to the variation of pressure and temperature.
\end{abstract}

(c) 2017 Elsevier Ltd. All rights reserved.

\section{Introduction}

Fossil fuels have long been used as the main energy source for our societal development. However, with the issues of increasing stringent emission regulations, rising oil prices and the finite supply of fossil fuels, it is necessary to search for sustainable and environment-friendly energy source. One of the promising candidates for partial replacement of fossil fuels is the biofuel of second generation where large quantities of sustainable lignocellulosic biomass are used as feedstocks. Among the production routes currently proposed to transform solid biomass into liquid fuels, the base-catalyzed depolymerization of lignin [1] or thermochemical pyrolysis $[2-4]$ processes become mature technologies. However, the produced bio-oils contain large amount of oxygen in their molecular constitution (up to $45 \mathrm{wt} \%$ mainly from phenolic or sim-

\footnotetext{
* Corresponding author at: State Key Laboratory of High Temperature Gas Dynamics, Institute of Mechanics, Chinese Academy of Sciences, No. 15 Beisihuanxi Road, Beijing 100190, China.

E-mail address: yi.wu@imech.ac.cn (Y.Wu).
}

ilar types as well as large amount of aromatics and olefins) which potentially impact the ability of these biofuels to be directly used as drop-in replacement of existing petroleum-based fuels [5]. Accordingly, biofuels derived via these processes must go through upgrading processes to remove these oxygenated compounds and produce a fuel that contains only hydrocarbons [6]. Upgrading processes are expensive, and their costs increase as the levels of oxygenated compounds in the final fuel product decrease [7]. To reduce upgrading costs and produce drop-in biofuels at a market-competitive price, it is therefore economically desirable to leave a small fraction of oxygenated compounds in the final upgraded fuels. For this approach to be technically viable, it must be shown that the presence of these oxygenated compounds in the final fuel blends does not adversely affect the combustion properties of fuels and so the operation of existing engines. It is therefore necessary at the first step to understand the fundamental combustion properties of these oxygenated compounds presents in upgraded advanced biofuels and the potential effects of these oxygenates additives on traditional petroleum-based hydrocarbon fuels. 
Laminar flame speed is one of the key parameters in studying the combustion process and it contains fundamental information of reactivity, diffusivity and exothermicity of combustible mixtures. It is also useful to validate new developed chemical kinetic mechanisms as well as turbulent combustion models [8-11]. Numerous previous studies have delivered significant insights into the effects of the addition of oxygenates on the laminar flame speeds of gasoline or diesel fuels [10,12-19]. For instance, Dirrenberger et al. [14] measured laminar burning velocity of gasoline with addition of ethanol using a heat flux burner. In their work, adiabatic laminar burning velocity measurement was firstly conducted for a gasoline model fuel consists of n-heptane, iso-octane and toluene mixtures at condition of $\mathrm{P}=0.1 \mathrm{MPa}$ and $\mathrm{T}=358 \mathrm{~K}$. Measurements were then performed for blends mixed by this model gasoline fuel and ethanol to address the influence of ethanol as an oxygenated additive on laminar flame speed of gasoline at atmospheric pressure condition. In Varea et al.'s [10] work, measurement conditions of laminar flame speed were extended to high pressure $\mathrm{P}=1 \mathrm{MPa}$ for the blends of iso-octane and ethanol using a spherical flame configuration. Most of the previously studied oxygenated fuels added to surrogate gasoline are referred to oxygenate produced from bio-chemical production route i.e. they are small molecule weight alcohol oxygenates such as butanol and ethanol etc. To the best of our knowledge few previous work deals with the effects of oxygenates present in upgraded lignocellulosicbiomass pyrolysis oils issued from biofuels of second generation. These oxygenated compounds found in upgraded biomass pyrolysis oil are typically high molecular weight fuels with carbon number varying from $C_{5}$ to $C_{11}$ which have higher boiling point compared to alcohol oxygenates [6]. Fig. 1 illustrates that the main oxygenated molecules found in upgraded biomass pyrolysis oil are able to cover the gasoline boiling point range. Furan molecules whose boiling points lower than $393 \mathrm{~K}$ (2,5-dimenthyl-furan, methyltetrahydrofuranand 2-methylfuran) are located in light fuel fraction. Oxygenated fuels such as anisole, 2-hexanone, phenol or ethylvalerate are covering the 393-453 K temperature range representing of the medium fuel fraction. Oxygenated molecules having boiling points $>453 \mathrm{~K}$ including 2,4-xylenol, 1, 2-dimethoxy benzene, guaiacol, p-cresol or 4-propylanisole covers the heavy fuel fraction. These oxygenates to be components of second generation biofuels acting as drop-in additive to the gasoline could potentially influence the performance of the existing combustion systems. The present work aims to experimentally investigate the laminar flame speed of these oxygenates compounds and their potential effects acting on the laminar flame speed of petroleumbased gasoline fuels.

An analysis of the published literature reveals that laminar flame speed for some of these pure oxygenates have been previously investigated, especially for furan molecules and ethylvalerate [20-23]. Indeed, Ma et al. [22] reported experimental measurements of laminar flame speed of 2-methylfuran and isooctane blends fuels at various preheating temperatures $T=333-393 \mathrm{~K}$ and equivalence ratios $\varphi=0.8-1.4$. Dayma et al. [23] measured laminar flame speed of ethylvalerate/air mixtures at $\mathrm{T}=423 \mathrm{~K}$ and atmospheric pressure conditions. Wu and al. [21] measured the laminar flame speed of a 2,5-dimethylfuran/air mixture at elevated pressures $\mathrm{P}=0.1-0.75 \mathrm{MPa}$ over a wide range of equivalence ratio $\varphi=0.8-1.2$. However, substantial disparities in laminar flame speeds of these oxygenate were observed among different measurements making it difficult to use these experimental data to validate the kinetic mechanism. Moreover, very limited data were reported for the other oxygenates located at medium or heavy fuel fraction. Consequently, for a better understanding of these oxygenates combustion process it is still necessary to complete these pure oxygenates/air flame studies over a wider conditions of temperature, pressure and equivalence ratio ranges. The first purpose of this study is to investigate laminar flame speed of three different oxygenates (anisole, 4-methylanisole and ethylvalerate) present naturally in pyrolysis oil to be components of drop-in gasoline fuels using a high pressure Bunsen flame burner.

Apart of the necessity of measuring laminar flame speed of these pure oxygenates, the potential effect of these oxygenates additives on gasoline needs to be clarified i.e. laminar flame speed measurements of blends mixed by these oxygenates and petroleum based gasoline need to be conducted. However, commercial gasoline consists of hundreds or thousands chemical components and its composition varies among the different sites of production, a quantitative understanding of the role of the species composition on the laminar flame speed property is still complex to perform for the wide range of operating conditions similar with those encountered in real engines generally investigated. Therefore, utilization of component identified surrogate gasoline that can successfully reproduce the properties of commercial gasoline fuel is necessary [24-29]. In the present work, a surrogate gasoline to emulate the

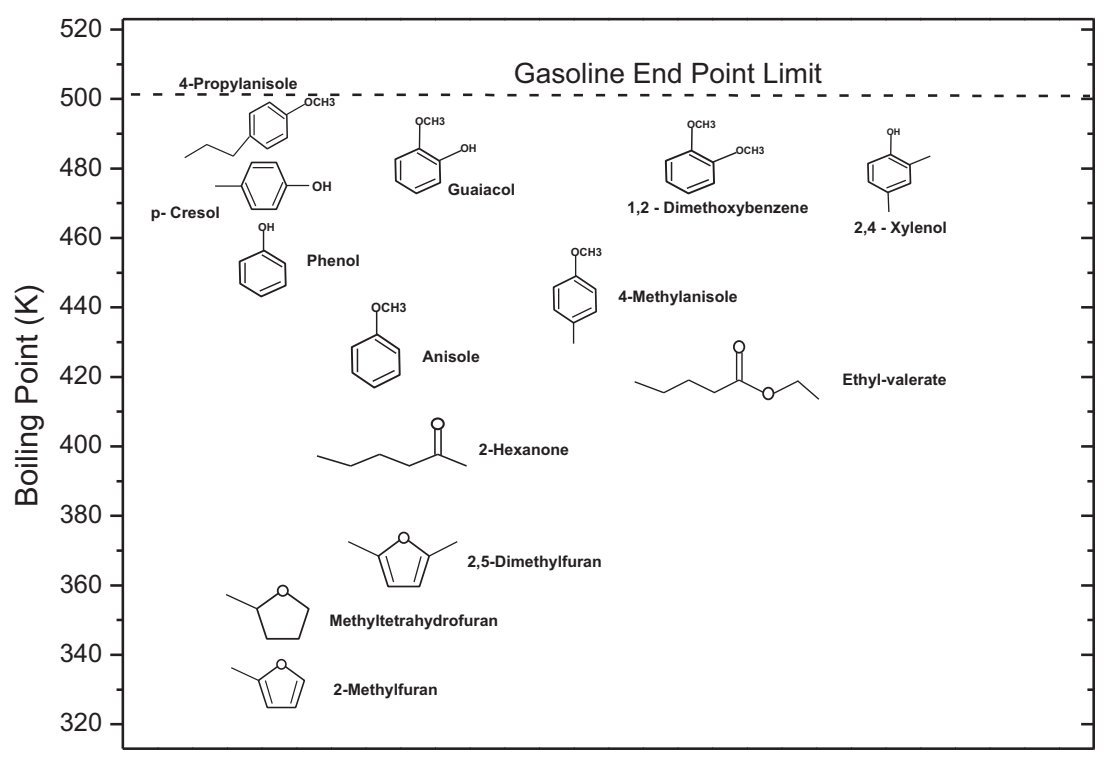

Fig. 1. Oxygenates distribution in function of the boiling point in a gasoline composition. 
commercial gasoline consists of five pure components: hexane, 2 , 3-dimethylbut-2-ene, cyclohexane, iso-octane and toluene is proposed. Hereby, as the petroleum based gasoline contains quite limited oxygenated compounds which can be neglected the surrogate gasoline proposed in the present work only consisted of hydrocarbon fuels [14-25]. The second purpose of the present study is therefore to experimentally elucidate if this five-component surrogate gasoline fuel is capable to reproduce the laminar flame speed property of commercial gasoline. To achieve this purpose, laminar flame speeds of this surrogate gasoline are measured over a large working conditions including temperature, pressure and equivalence ratio. These results are compared with literature found laminar flame speeds of surrogate gasoline fuels and commercial gasoline to validate the composition of the current surrogate gasoline. Finally, the last purpose of this study focuses on characterizing the influence of the addition of oxygenates acting on laminar flame speed properties of petroleum based gasoline fuels. To achieve this, the aforementioned surrogate gasoline fuel is mixed with different percentages of single oxygenated fuels. Measurements of laminar flame speeds of these blends over large working conditions including temperature, pressure and equivalence ratio variation effects are conducted and analyzed in details.

\section{Experimental setup and procedures}

\subsection{Experimental facility}

In this study, laminar flame speeds were measured using a high pressure Bunsen flame burner. The detailed description of the experimental apparatus can be found in the previous publication of $\mathrm{Wu}$ et al. [30], and only a brief introduction is given here. As illustrated in Fig. 2, the whole experimental apparatus consists of a high pressure Bunsen flame burner, the liquid fuel vaporization with gas feedings system and the optical diagnostic set-up. The premixed Bunsen flame burner allows establishing a steady conical laminar premixed flame stabilized on the outlet of a contoured nozzle. The contoured nozzle used in the present work has an outlet diameter $d_{1}=7 \mathrm{~mm}$. A concentric contoured nozzle of outlet diameter of $d_{2}=7.6 \mathrm{~mm}$ surrounding the central nozzle is used to produce a pilot flame to stabilize the flame in high pressure operating conditions. The whole burner is placed into a $\mathrm{N}_{2}$ ventilated high pressure chamber constructed in stainless steel with an inner surface of $100 \times 100 \mathrm{~mm}^{2}$ and a height of $511 \mathrm{~mm}$. A perforated brass plate, ceramic beads and a honeycomb straighten the flow in the chamber. With four large pressure resisting UV quartz windows it is accessible to probe the flame with optical imaging diagnostics. The preheating of the chamber and the gas feeding lines is performed by an electrical wire heater wrapped around its external surface. Thermocouples are placed at different position of the chamber to monitor the temperature uniformity throughout the pressure chamber while the chamber pressure is monitored with a piezoelectric transducer. The front view of the high pressure chamber with Bunsen flame burner is shown in Fig. 3.

The liquid fuel pressurized in a $1.0 \mathrm{~L}$ tank were delivered by a liquid flow controller (Bronkhorst mini-CORIFLOW) to a Controlled Evaporator and Mixer (CEM, Bronkhorst) which heats and mixes fuel vapor with $\mathrm{N}_{2}$ carrier gas at controlled mass flow rate and temperature. Additional nitrogen and oxygen controlled by two mass flow controllers (MFC) are mixed and used to reproduce the synthetic species composition of air and to modify the equivalence ratio of the heated fuel vapor/air mixtures. To prevent any condensation of the fuel vapor, the reactive mixture and the guard flow to generate high pressure environment are preheated with two circulation heaters before the entrance of the mixing cell.
A resume of literature reveals that various optical measurements methods have been proposed and used in the past in laminar flame speed measurements [9,31-33]. These mainly include flame emission imaging techniques i.e. chemiluminescence, the Shadowgraph/Schlieren image technique and the recently applied OH-PLIF technique. The optical technique implemented in the present work is based on the flame contour detection by using $\mathrm{OH}^{*}$ chemiluminescence image technique. The flame is recorded by a thermoelectrically cooled, 16- bit intensified CCD camera (Pi-Max 3, Roper Scientific) with a $1024 \times 1024$ array at 10 frames per second, so that the spatial resolution is about $40 \mu \mathrm{m}$ per pixel. The camera is equipped with an $\mathrm{f} / 2.8, \mathrm{f}=100 \mathrm{~mm}$, achromatic UV lens (CERCO) combined with an interference bandpass filter centered at $310 \mathrm{~nm}$ having a bandwidth of $10 \mathrm{~nm}$. The exposure time is kept constant at $10 \mu \mathrm{s}$. The intensification is also kept constant so that the flames captured show a weak sensitivity to the postprocessing parameters.

\subsection{Extraction of flame speed}

Bunsen flame method is a convenient and widely used approach in laminar flame speed measurements because of its advantages of simplicity and well defined flame structure [9,30,34-36,32]. Laminar flame speed is defined as the velocity at that a planar flame front travels relative to the unburned gas in direction normal to the flame surface [37]. For a conical flame, assuming that the flame speed is the same all over the entire surface area of the flame, the laminar flame speed can be derived based on the mass conservation between the outlet nozzle and the flame front. As shown in Fig. 4, the average flame velocity in the transverse plane is expressed by:

$\rho_{u} S_{L} A=Q_{m} \rightarrow S_{L}=Q_{m} /\left(\rho_{u} A\right)$

where $Q_{m}$ is the total mass flow rate of the fuel/air gaseous mixture, $\rho_{\mathrm{u}}$ is the unburned gas density. This method requires the knowledge of the total area of the flame surface $\boldsymbol{A}$, deduced in the present investigation by analyzing the $\mathrm{OH}^{*}$ chemiluminescence image of the flames. A Matlab program is developed to perform Abel inversion [38] of the recorded images to provide the 2-D boundary of the surface area at the reaction zone of the flame. The flame front used to calculate surface $\boldsymbol{A}$ is then obtained by taking the inside boundary of the surface area from the image after Abel inversion. Specific high frequency filtering function was used to smooth the resulting curve plotted in red line in Fig. 4(b) to obtain the final flame front. Once the flame front is determined, the flame area $\mathrm{A}$ is calculated by pivoting this flame front profile $f(x)$ along the burner axis using the following equation:

$A=2 \pi \int_{a}^{b} f(x) \sqrt{1+\left|f^{\prime}(x)\right|^{2}} d x$

where $a$ and $b$ are the boundary limits of integration. $f(x)$ is the flame contour profile function obtained by image processing. Assuming the axisymmetric condition of the flame, the final flame speed is the averaged value by using the flame surface area calculated from each half of the recorded images. It should be noted that the flame speed measured using the aforementioned equation is an averaged value of the entire flame surface which is different from the unstretched flame speed as this conical flame is affected by its strain and curvature effects. Fortunately, the difference between both values is found tiny and can be negligible in our experiments in regards the results present in Refs $[9,30,32]$. 

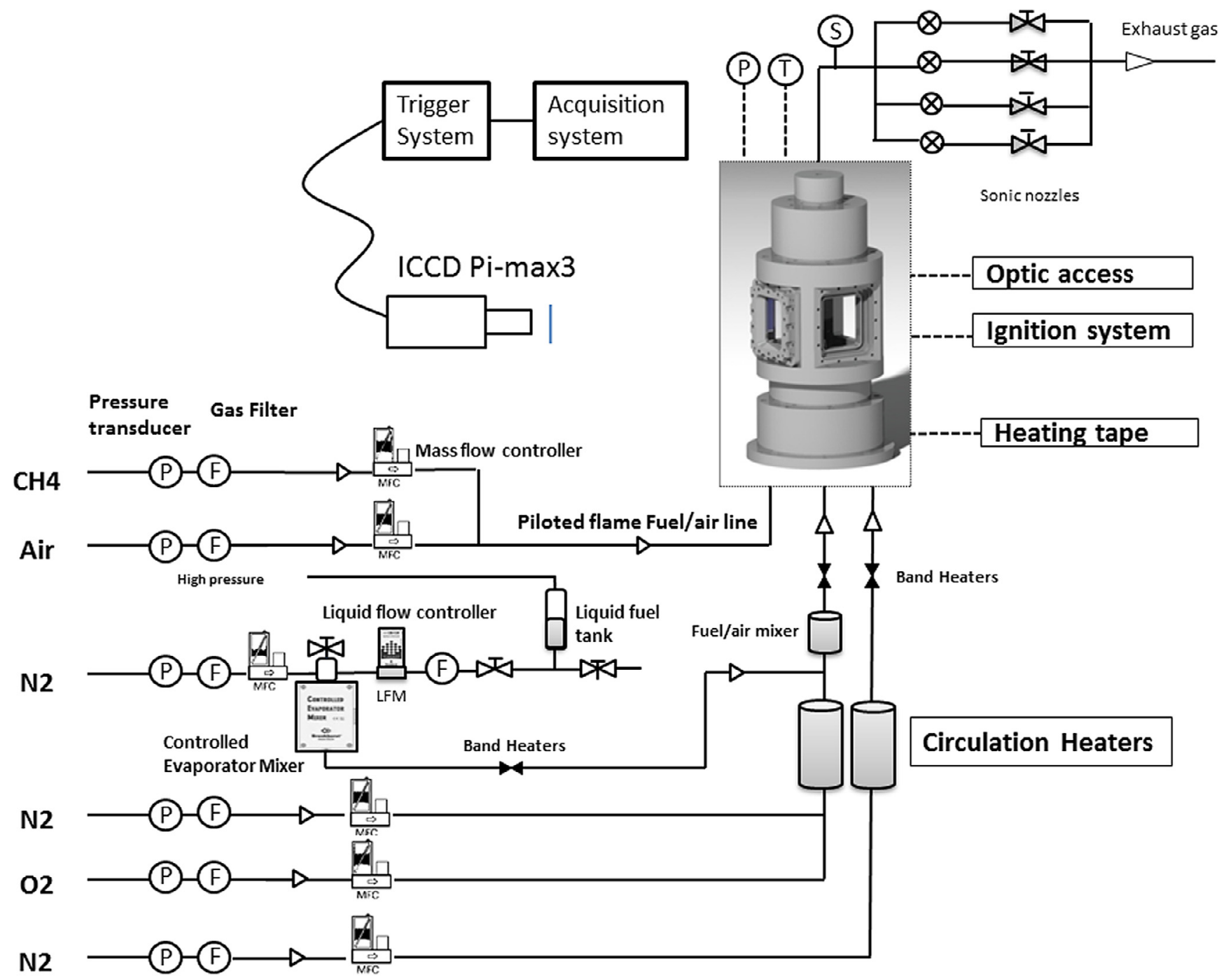

Fig. 2. Experimental set-up.
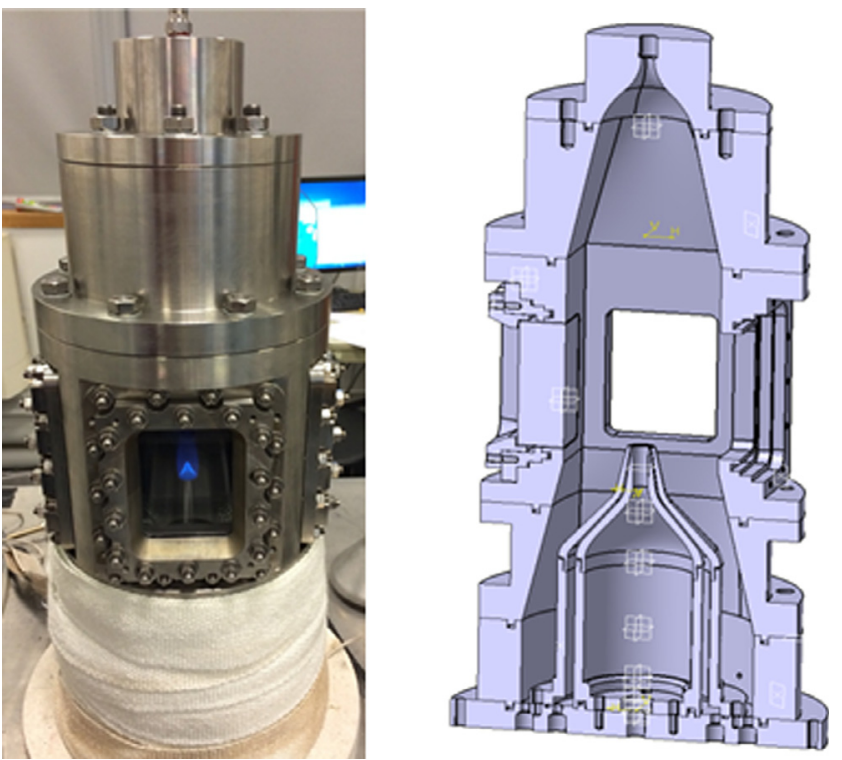

Fig. 3. High pressure chamber.

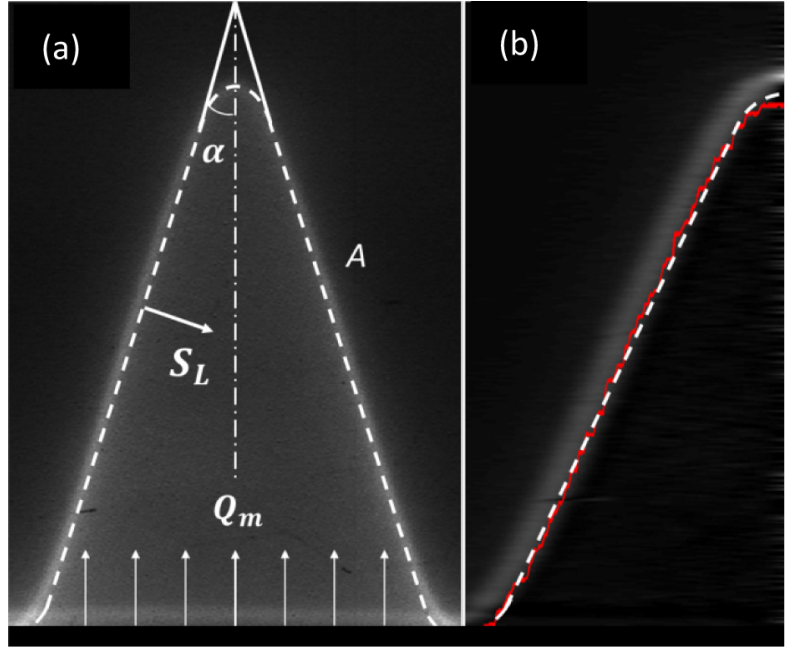

Fig. 4. Determination of the flame surface area (a) original $\mathrm{OH}^{*}$ chemiluminescence image, (b) Left half of Abel-inverted image (red line is the original curve found by taking inside front of Abel-inverted image, dash line is the line used in flame speed calculation obtained after smoothing function). 


\subsection{Measurements uncertainties}

For each measurement condition reported in this work, 30 instantaneous images are systematically recorded and the resulting laminar flame speed is determined by data processing of averaged images deduced from the set of the instantaneous images. The main source of the measurement errors is associated with gas/liquid flow delivery system $\left(\mathrm{U}_{\mathrm{Qm}}\right)$ and the uncertainty of the calculated flame area image $\left(\mathrm{U}_{\mathrm{A}}\right)$ which determined by the camera resolution. The uncertainty of the total flow rate comes from the mass flow controller uncertainty $(0.5 \%$ of reading $+0.1 \%$ full scale) which are estimated to be $\sim 2 \%$, and uncertainty derives from the camera spatial resolution which is estimated to be $\sim 3 \%$. The overall uncertainty is calculated to be within $\sim 4 \%$ (from the relation $\left.\sqrt{U_{\mathrm{Qm}}^{2}+U_{A}^{2}}\right)$ for all the laminar flame speeds that are recorded at atmospheric pressure conditions. For high pressure measurements $\mathrm{P}>0.5 \mathrm{MPa}$, the measurement uncertainty can be amplified due to the flame stability. Indeed, the fluctuation of the position of the flame displays an artificial thickening of the flame front during the time integration of the signal on the camera. This effect modifies the position of the flame contours (2-3 pixels) giving a maximum uncertainty of $\sim 7 \%$ in the worst situation.

\section{Experimental results and discussion}

The measurement results of laminar flame speed for pure oxygenates fuel (anisole, 4-mythlanisole and ethylvalerate) at $\mathrm{T}=423 \mathrm{~K}, \mathrm{P}=0.1 \mathrm{MPa}$ and $\varphi=0.6-1.3$ will be firstly presented in this section. Then, a five-component surrogate fuel is proposed to emulate the laminar flame speed property of commercial gasoline. In order to validate the composition of the proposed surrogate fuel, laminar flame speeds of this five-component surrogate are measured over a large working condition $\mathrm{T}=358-473 \mathrm{~K} ; \mathrm{P}=0.1$ $0.8 \mathrm{MPa}$ and $\varphi=0.6-1.3$ and compared with literature results of surrogate fuel and commercial gasoline. Finally, in order to characterize the influence of the addition of oxygenates on the laminar flame speed of gasoline, measurements are performed for blends mixed by surrogate gasoline and different percentage of oxygenates $(5 \%, 10 \%, 20 \%, 30 \%, 50 \%$ and $75 \%)$ over a large range of conditions $\mathrm{T}=358-473 \mathrm{~K}, \mathrm{P}=0.1-0.8 \mathrm{MPa}$ and $\varphi=0.6-1.3$. The effect of oxygenates addition to gasoline fuel will be further discussed in taking account of the variation of temperature and pressure.

\subsection{Laminar flame speed of pure oxygenates}

The oxygenated residual components from upgraded pyrolysis oil studied here are molecules located in the medium fuel fraction: anisole, 4-methyanisole and ethylvalerate. Laminar flame speed of phenol is not studied in the present work because phenol is generally considered not suitable used as drop-in fuel due to its corrosivity and low solubility in hydrocarbon. Moreover, its toxicity requires extreme condition of safety during manipulations. Details of the physical properties of oxygenates studied in the present work are reported in Table 1 . Anisole and 4-methylanisole (i.e. methyl aryl ethers) appear to be the best drop-in fuel components for gasoline seeing they significantly increase research octane number (RON) and slightly reduce vapor pressure without significant negative fuel property effects [6]. Potentially, mixing of gasoline with these methyl aryl ethers will provide a fuel with a higher octane rating which could be less prone to auto-ignition and be able to support a greater rise in temperature during the compression stroke of an internal combustion engine without autoigniting, thus allowing more power to be extracted from the Otto-Cycle.The interest of ethylvalerate comes from the progresses in biomass processing which have made lignocellulose more attractive for the production of liquid biofuels. Indeed, levulinic acid obtained from lignocellulose can be converted into esters by hydrogenation and esterification. Similar with anisole and 4methylanisole this molecule has an elevated octane number ( 100). The use of blends of ethylvalerate with gasoline shows a favorable increase in octane number without deterioration of properties such as corrosion and gum formation. Ethylvalerate blending also increases the gasoline density and oxygen-content, reduces its volatility and lowers its content of aromatics, olefins and sulfur [39]. These favorable properties of ethlyvalerate indicate the potential benefits of using ethlyvalerate as a drop-in fuel without any modification of the existing engines.As exhibited in Fig. 5, laminar flame speed of anisole, 4-methylanisole and ethylvalerate at $\mathrm{T}=423 \mathrm{~K}, \mathrm{P}=0.1 \mathrm{MPa}$ and $\varphi=0.6-1.3$ are presented. It can be observed that whatever the equivalence ratio methyl anisole and ethylvalerate fuels have similar laminar flame speeds values. Meanwhile the laminar flame speed of anisole is always higher compared to that of 4-methylanisole and ethylvalerate. It is observed that the maximum deviation between the different flame speed values is up to $5 \mathrm{~cm} / \mathrm{s}$ when approaching stoichiometric conditions. Fig. 6 displays the obtained results for ethylvalerate with the few data found in literature $[23,40]$. Our measurements are firstly compared with the results reported by Dayma et al. [23] who performed measurements of laminar flame speeds at the same operating conditions using a spherical expanding flame. The present work gives general faster flame speeds for all the investigated equivalence ratio conditions with a maximal difference of $7 \mathrm{~cm} / \mathrm{s}$ at approaching stoichiometry conditions. Meanwhile compared to the literature experimental results, our experimental results are more approaching to the simulation results proposed by Dayma et al. [23] especially at lean and rich side. Also plotted in Fig. 6 are the recent data recorded by Katshiatshia et al. [40] using heat flux method. Although these measurements were performed at lower preheating temperatures $\mathrm{T}=318$ $338 \mathrm{~K}$, the representation of the variation of the laminar flame speeds of ethylvalerate with equivalence ratio for various preheating temperatures highlights the sensitivity of temperature on laminar flame speeds in the temperature range 318-423 K.

\subsection{Laminar flame speed of surrogate gasoline}

Hereby, we proposed a five-component surrogate fuel to match the commercial gasoline. The methodology used to define the surrogate fuel was the following. First, a reference commercial gasoline retained for the present study was analyzed. Results of these analyses have shown that this gasoline fuel is composed of $57 \%$ of alkanes, $8 \%$ of olefins and 35\% of aromatics compounds. From this chemical composition, a determination of the proportions of

Table 1

Oxygenates properties.

\begin{tabular}{|c|c|c|c|c|}
\hline Fuel & Formula & $\begin{array}{l}\text { Boiling point } \\
(\mathrm{K})\end{array}$ & $\begin{array}{l}\text { Density } \\
\left(\mathrm{kg} / \mathrm{m}^{3}\right)\end{array}$ & RON \\
\hline Anisole & $\mathrm{CH}_{3} \mathrm{OC}_{6} \mathrm{H}_{5}$ & 428 & 660 & 119 \\
\hline 4-methylanisole & $\mathrm{C}_{8} \mathrm{H}_{10} \mathrm{O}$ & 447 & 669 & $>130$ \\
\hline Ethylvalerate & $\mathrm{C}_{7} \mathrm{H}_{14} \mathrm{O}_{2}$ & 418 & 875 & $\sim 100$ \\
\hline
\end{tabular}




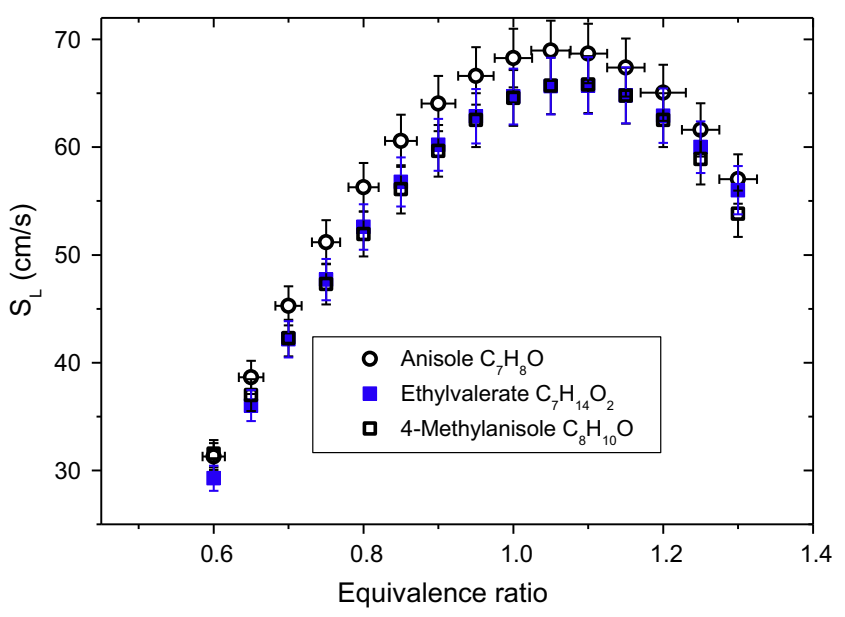

Fig. 5. Laminar flame speeds of anisole, 4-methylanisole and ethylvalerate at $\mathrm{T}=423 \mathrm{~K}, \mathrm{P}=0.1 \mathrm{MPa}$ and $\varphi=0.6-1.3$.

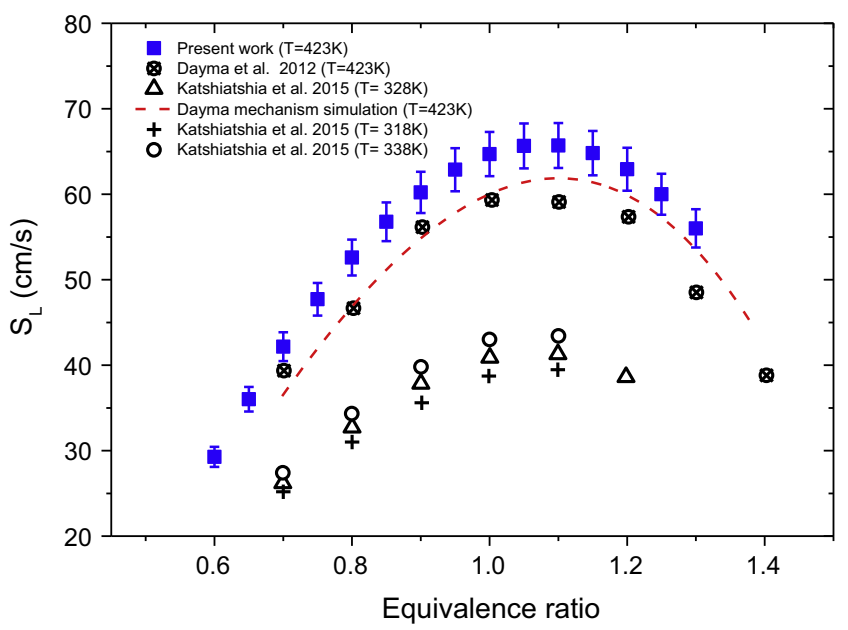

Fig. 6. Comparison of laminar flame speeds of ethylvalerate between our measurements and literature results $[23,40]$.

compounds was then performed in order to match experimental data of the commercial fuel such as distillation curve, octane rating and density etc. The best agreement has consisted of using only five pure compounds: hexane (24.31 wt\%), 2, 3-dimethylbut-2ene $(8.15 \mathrm{wt} \%)$, cyclohexane (14.21 wt\%), iso-octane (17.75 wt\%) and toluene $(35.58 \mathrm{wt} \%)$ with an averaged formula of $\mathrm{C}_{6.6672} \mathrm{H}_{11.6045}$. In traditional petroleum-based gasoline fuels, the oxygenated components are quite limited which can be neglected. The same consideration with previously proposed surrogate gasoline in literature [24-29], in the present work the surrogate gasoline composition only consisted of hydrocarbon fuels. Fractions of alkanes and aromatics compounds (i.e. toluene in the current study) in the present surrogate gasoline were closed to those mainly present in the commercial gasoline fuel [41]. The resultant RON of our surrogate gasoline was estimated to 94.2 calculated using the method proposed from the works of Morgan et al. [42] and Ghosh et al. [43].Measurements of laminar flame speeds were initially recorded at $\mathrm{T}=358 \mathrm{~K}, \mathrm{P}=0.1 \mathrm{MPa}$ and $\varphi=0.6-1.3$ and then compared with measurements results of the commercial gasoline and surrogate gasoline fuels studied in the work of Dirrenberger et al. [14]. For information, the commercial gasoline fuel studied in the reference work was provided by TOTAL (Ref. IFPen: TAE7000) with an estimated RON of 95.6 which is very close with that of our surrogate fuel. Chemical analysis of this gasoline fuel gives a composition of $10.5 \%$ of n-alkanes, $40.7 \%$ of iso-alkanes and $32.5 \%$ of aromatic compounds. The average molecular formula is then $\mathrm{C}_{6.76} \mathrm{H}_{12.46} \mathrm{O}_{0.08}$. The composition of the surrogate fuel defined in the work of Dirrenberger et al. [14] to match the properties of the TAE7000 was the followings: $13.7 \%$ n-heptane, $42.9 \%$ iso-octane and $43.4 \%$ of toluene and the average chemical formula was $\mathrm{C}_{7.34} \mathrm{H}_{12.43} \mathrm{O}_{0.00}$. A RON number of 98.1 were then estimated. Properties comparisons are listed in Table 2.Fig. 7 displays the measurements recorded for the three fuels: surrogate proposed in the current work, commercial gasoline TAE7000 and surrogate proposed in the work of Dirrengberger et al. [14]. Very close agreement between laminar flame speeds are observed for the complete range of the investigated equivalence ratio. Despite the similarity between the average chemical formula of the commercial gasoline and our surrogate fuel, a slight overestimation of our measurements was observed for equivalence ratio of $\varphi=1.1-1.3$. A systematic underestimation of laminar flame speeds between the surrogate fuel referenced in [14] and our surrogate fuel was also observed whatever the equivalence ratio. Considering that the discrepancies between laminar flame speeds are small $(\sim 3 \mathrm{~cm} / \mathrm{s}$ at $\varphi=1.2$ ) and comparable to the measurement uncertainty, the proposed surrogate gasoline fuel in the present work is a good support to reproduce the laminar flame speeds of commercial gasoline fuels.The effect of the preheating temperature on the laminar flame speed of our surrogate fuel was then complimented by performing additional measurements at two higher temperature conditions: $\mathrm{T}=423$ and $473 \mathrm{~K}$. Results presented in Fig. 8 resume the variation of the preheating temperature on the laminar flame velocity of such surrogate fuel. As predicted, with increase of unburned reactant temperature, the laminar flame speed of surrogate increases because of the increased chemical rates and thermal and mass diffusivities $[44,45]$. Finally, in order to elucidate the effects of pressure variation on laminar flame speed, measurements were performed for various pressures ranging between $\mathrm{P}=0.1$ $0.8 \mathrm{MPa}$. The equivalence ratios investigated are in the range of $\varphi=0.7-0.9$. The preheating temperature is fixed at $\mathrm{T}=423 \mathrm{~K}$. The measured flame speeds are plotted in Fig. 9. As originally intended, the flame speed should decrease linearly with logarithmic pressure [46]. From these results, the flame speed pressure dependence using power law $S_{u}=S_{u}^{0}\left(\frac{P}{P_{0}}\right)^{\beta}$ was calculated and the $\beta$ coefficient values are $\beta=0.247,0.253$ and 0.298 corresponding to equivalence ratio of $\varphi=0.9,0.8$ and 0.7 were found.

Table 2

Properties comparison between surrogate in present work and literature surrogate/commercial gasolines.

\begin{tabular}{|c|c|c|c|}
\hline & $\begin{array}{l}\text { Surrogate in present work } \\
\text { (24.31\% (wt) hexane, } 8.15 \% \\
\text { 3-dimethylbut-2-ene, } \\
14.21 \% \text { cyclohexane, } 17.75 \% \\
\text { iso-octane and } 35.58 \% \text { toluene) }\end{array}$ & $\begin{array}{l}\text { Surrogate in Ref. [14] } \\
\text { (13.7\% (vol.) n-heptane, } \\
42.9 \% \text { iso-octane, } 43.4 \% \text { toluene) }\end{array}$ & $\begin{array}{l}\text { Commercial gasoline } \\
\text { (TAE7000) }\end{array}$ \\
\hline Formula & $\mathrm{C}_{6.6672} \mathrm{H}_{11.6045}$ & $\mathrm{C}_{6.76} \mathrm{H}_{12.46} \mathrm{O}_{0.08}$ & $\mathrm{C}_{7.34} \mathrm{H}_{12.43}$ \\
\hline Estimated RON & 94.2 & 98.1 & 95.6 \\
\hline
\end{tabular}




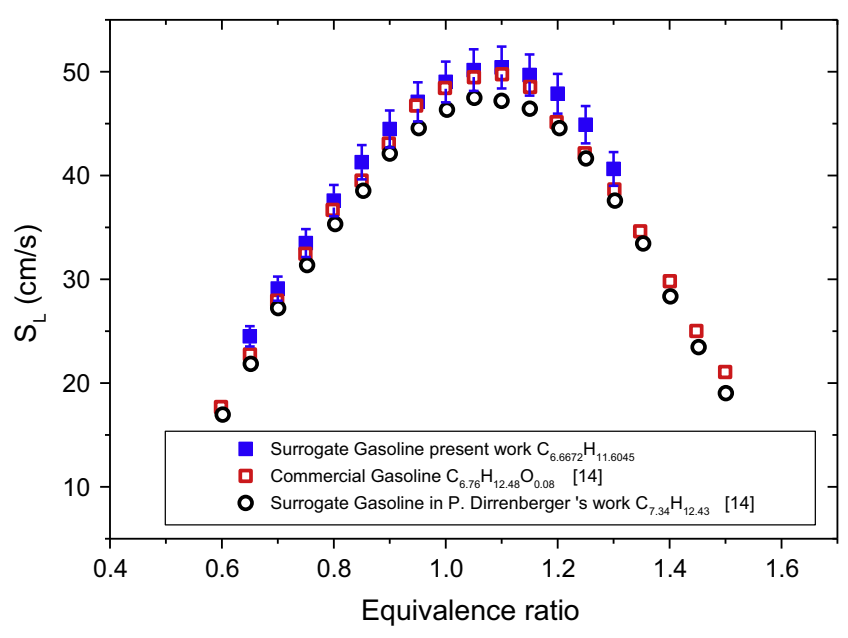

Fig. 7. Variation of the laminar flame speeds of our surrogate gasoline, commercial gasoline and surrogate gasoline referenced in [14] in function of the equivalence ratio $\mathrm{T}=423 \mathrm{~K}, \varphi=0.6-1.3$ and $\mathrm{P}=0.1 \mathrm{MPa}$.

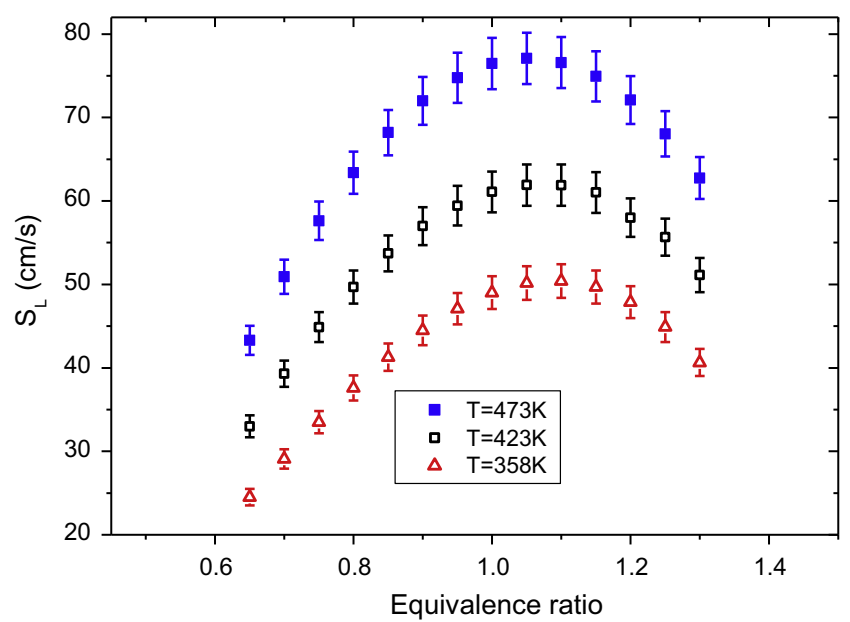

Fig. 8. Evolution of the laminar flame speed of our surrogate fuel in function of the equivalence ratio for three preheating temperatures: $T=358,423,473 \mathrm{~K}$, $\mathrm{P}=0.1 \mathrm{MPa}$ and $\varphi=0.65-1.3$.

\subsection{Laminar flame speed of surrogate gasoline/oxygenate blends}

It has been shown in the above section that the surrogate proposed in the current work is appropriate to have similar combustion characteristics with commercial gasoline in practical conditions. For a better clarity, this surrogate will be referenced in the following as SA0. In a first step, mixtures with different amounts of oxygenates were prepared in two groups. The first group mixtures consist of the SAO (i.e. previously proposed fivecomponent surrogate gasoline) with different mass fraction of anisole. Using this approach, the RON value of the resultant mixtures ranges from 94.2 to 119 . The second group i.e. ST0 allows for a substitution of the percentage of toluene in SAO by the same percentage of anisole with a RON varying from 94.2 to 94.3. Details of the mixture compositions investigated are given in Table 3. To simplify the experiments, only anisole has been added in the five component surrogate gasoline in the present work. The use of a large range of anisole concentration was dictated on the basis to get a wide variation of the laminar flame speeds but also that the RON value can vary over a large domain (estimation between 94.2 and 119).

\subsubsection{Mixtures of SAO/Anisole}

In order to study the influence of the addition of oxygenates on the laminar flame speed of SA0, measurements have been made for mixtures of SAO containing various mass fraction of anisole varying from 0 to $100 \%$. The comparison of the laminar flame speeds in function of the equivalence ratio is shown in Fig. 10. In these experiments, measurements were conducted at atmospheric pressure and a preheating temperature of $\mathrm{T}=423 \mathrm{~K}$. In general, it is observed that the laminar flame speed increases with the percentage of anisole contained into the mixtures over the whole equivalence ratio range measured except that $90 \%$ (wt) SA0 + $10 \%(w t)$ anisole is slightly lower than SA0 which is remained in measurements uncertainties as shown with error bars in Fig. 10. The peak value of laminar flame speeds for each mixture is located around $\varphi=1.1$ with a variation of the peak value of about $15 \%$. In order to get a better understanding, the aforementioned results were reported in function of the percentage of anisole as shown in Fig. 11. A linear variation of the laminar flame speed with the percentage of oxygenates is then observed for all the equivalence ratio

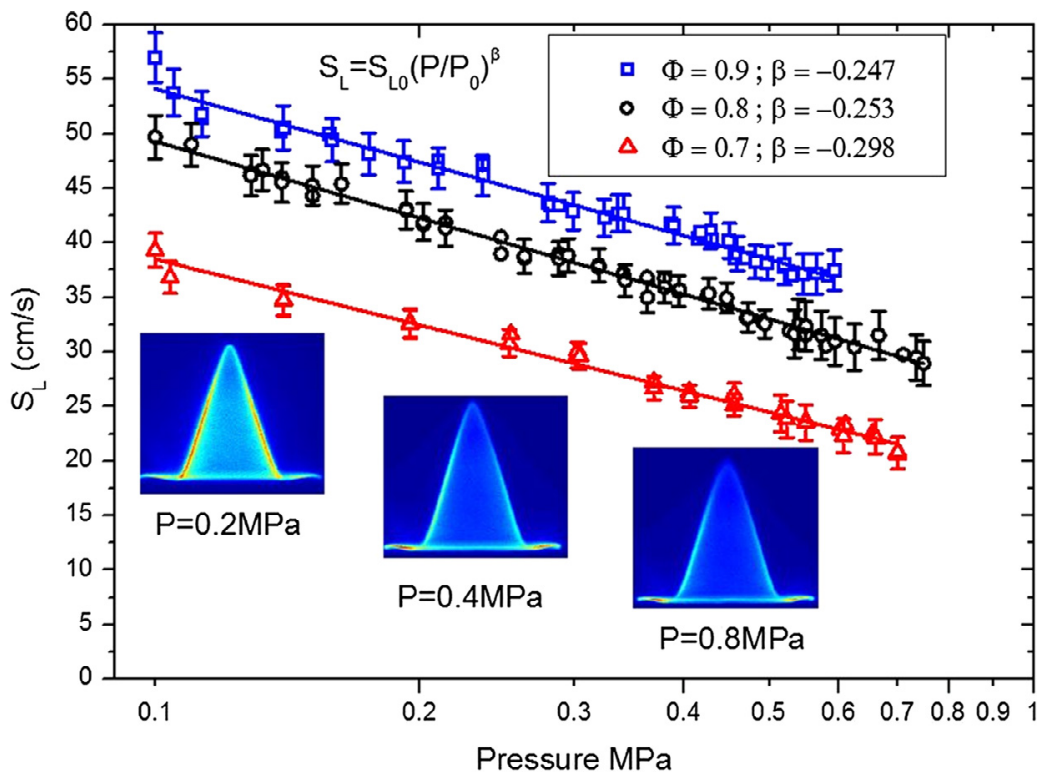

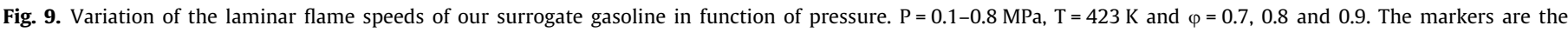
experimental data and the lines are the fits. 
Table 3

Compositions of fuel mixtures by mass.

\begin{tabular}{|c|c|c|c|c|c|c|c|}
\hline $\begin{array}{l}\text { Mixture } \\
\text { (wt\%) }\end{array}$ & $\begin{array}{l}\text { Hexane } \\
\text { (wt\%) }\end{array}$ & $\begin{array}{l}\text { 2,3 dimethyl-2-butene } \\
\text { (wt } \% \text { ) }\end{array}$ & $\begin{array}{l}\text { Cyclohexane } \\
\text { (wt\%) }\end{array}$ & $\begin{array}{l}\text { Isooctane } \\
\text { (wt\%) }\end{array}$ & $\begin{array}{l}\text { Toluene } \\
\text { (wt\%) }\end{array}$ & $\begin{array}{l}\text { Anisole } \\
\text { (wt\%) }\end{array}$ & $\begin{array}{l}\text { Estimated } \\
\text { RON }\end{array}$ \\
\hline SAO & 24.31 & 8.15 & 14.21 & 17.75 & 35.58 & 0 & 94.2 \\
\hline $90 \%$ SA0 $+10 \%$ anisole & 21.88 & 7.35 & 12.8 & 15.98 & 31.98 & 10 & 97.8 \\
\hline $80 \%$ SA0 $+20 \%$ anisole & 19.45 & 6.52 & 11.37 & 14.2 & 28.42 & 20 & 100.1 \\
\hline $70 \%$ SA0 $+30 \%$ anisole & 17.02 & 5.71 & 9.95 & 12.43 & 24.87 & 30 & 102.8 \\
\hline $50 \% \mathrm{SA} 0+50 \%$ anisole & 12.16 & 4.08 & 7.11 & 8.88 & 17.77 & 50 & 107.7 \\
\hline $30 \%$ SA0 $+70 \%$ anisole & 6.08 & 2.04 & 3.55 & 4.44 & 8.88 & 75 & 113.2 \\
\hline $0 \%$ SA0 $+100 \%$ anisole & 0 & 0 & 0 & 0 & 0 & 100 & 119 \\
\hline ST0 & 24.31 & 8.15 & 14.21 & 17.75 & 0 & 35.53 & 94.3 \\
\hline
\end{tabular}

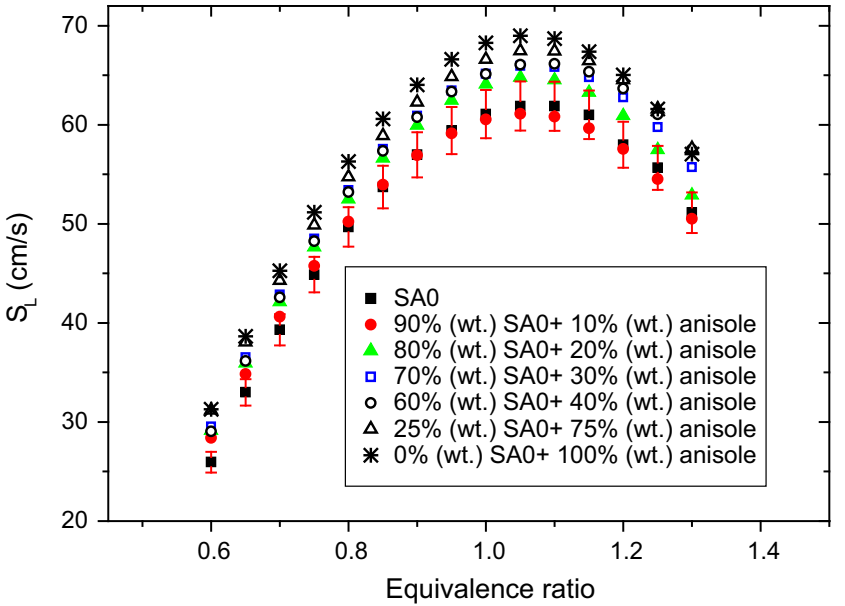

Fig. 10. Laminar flame speed of the mixtures of SA0 with $10 \%, 20 \%, 30 \%, 50 \%, 75 \%$ and $100 \%$ anisole. $\mathrm{T}=423 \mathrm{~K}, \mathrm{P}=0.1 \mathrm{MPa}$ and $\varphi=0.6-1.3$.

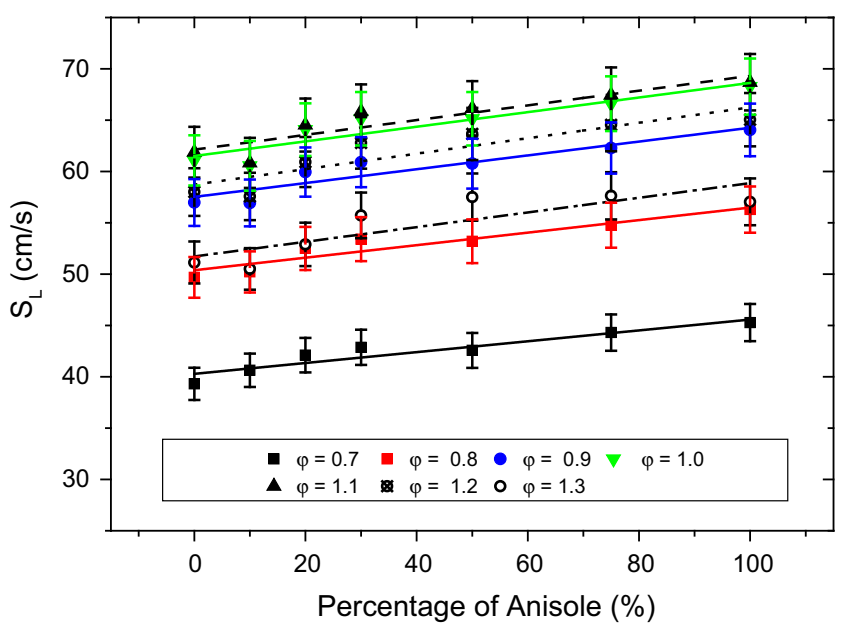

Fig. 11. Variation of the laminar flame speed of the mixture in function of the anisole fraction: $\mathrm{T}=423 \mathrm{~K}, \mathrm{P}=0.1 \mathrm{MPa}$ and $\varphi=0.6-1.3$. The markers are the experimental data and the lines are the fits.

conditions. The slope of this variation increases with equivalence ratio at the range of $\varphi=0.7-1.1$ and tends to a maximum value at $\varphi=1.1-1.2$, then decrease after $\varphi>1.2$. The exact value of the slope is listed in Table 4. For a practical view of combustion in engi-

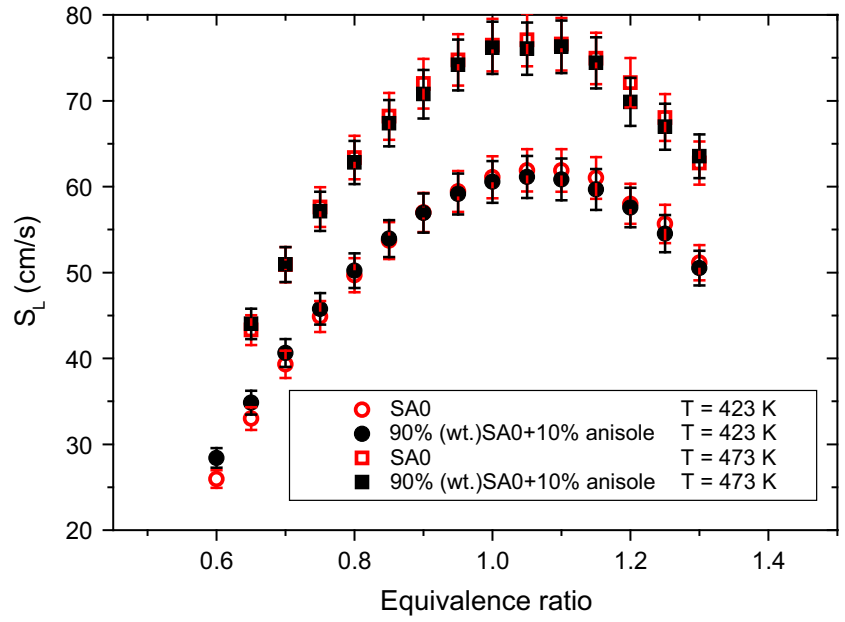

Fig. 12. Variation of the laminar flame speed of the SA0 and $90 \%$ (wt)SA0 + $10 \%$ (wt) anisole mixtures at two preheating temperatures $\mathrm{T}=423,473 \mathrm{~K}, \mathrm{P}=0.1 \mathrm{MPa}$ and $\varphi=0.6-1.3$.

nes, and considering that the content of oxygenates in a biofuel of second generation can reach a maximum level of $40 \%$, the resultant laminar flame speeds can potentially increase of a maximum value of $\sim 2-3 \mathrm{~cm} / \mathrm{s}$. Note also that the laminar flame speed of biogasolines with a maximum percentage of $10 \%$ of oxygenates will be relatively insensitive to the quantity of oxygenates and so, will not significantly modify the combustion characteristics of an internal combustion engine. As the RON value increases in function of the amount of oxygenates, the increase of the laminar flame speed could be also used to promote combustion with higher flame speeds without sacrificing the octane rating as shown in Fig. 10. Laminar flame speeds of the SA0 and $90 \%(w t)$ SA0 + $10 \%(w t)$ anisole mixtures, at two preheating temperatures (i.e. 423 and $473 \mathrm{~K}$ ) are shown in Fig. 12. Both mixtures exhibit comparable flame speeds for the two preheating temperatures investigated. These results indicate that the effect of the addition of few contents of oxygenates into the reference surrogate gasoline remains similar with temperature variation. The pressure behavior of the laminar flame speeds of the SA0, 50\% (wt) SA0 + 50\% (wt) anisole mixture and pure anisole were measured and compared in Fig. 13. As scheduled, the laminar flame speeds for the three surrogates follow power-law pressure dependence as expressed $S_{u}=S_{u}^{0}\left(\frac{P}{P_{0}}\right)^{\beta}$. The power exponents obtained with fitting experimental data are the followings: -0.3187 for the SA0, -0.3503 for $0 \%$ (wt) SA0 $+100 \%$ $(\mathrm{wt})$ anisole and -0.3536 for $50 \%(w \mathrm{t}) \mathrm{SAO}+50 \%(\mathrm{wt})$ anisole mix-

Table 4

Slope values with linear fitting for different equivalence ratios corresponding to Fig. 11.

\begin{tabular}{|c|c|c|c|c|c|c|c|}
\hline$\varphi$ & 0.7 & 0.8 & 0.9 & 1.0 & 1.1 & 1.2 & 1.3 \\
\hline Slope values & 0.053 & 0.061 & 0.067 & 0.071 & 0.072 & 0.075 & 0.071 \\
\hline
\end{tabular}




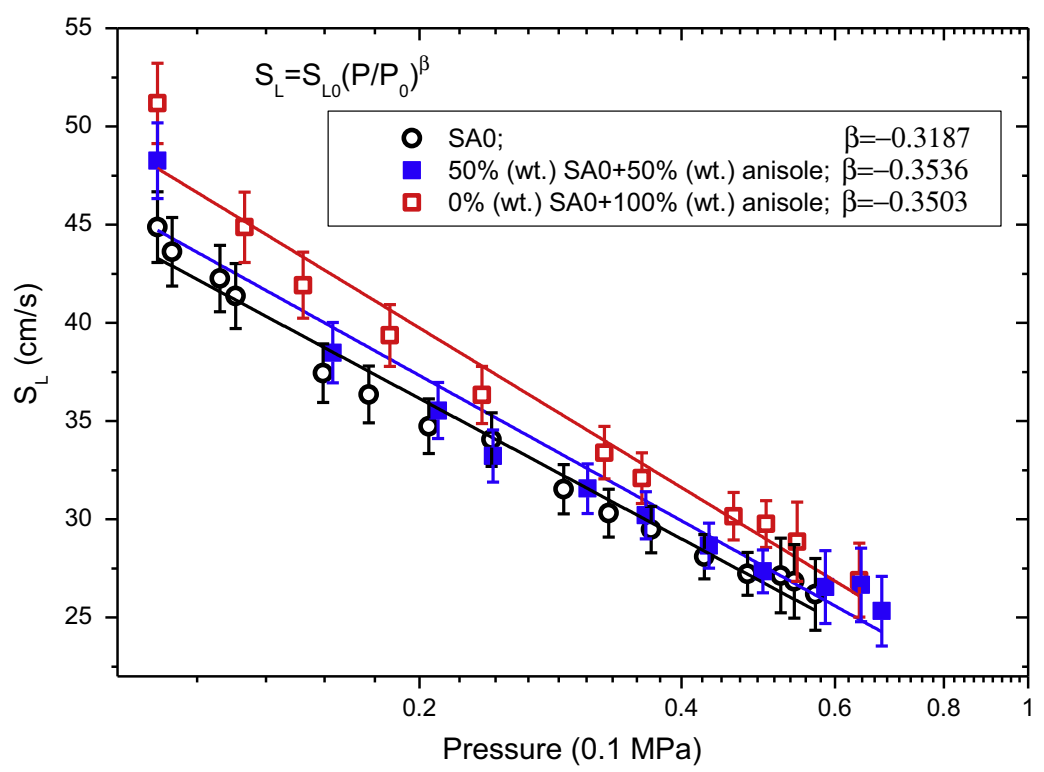

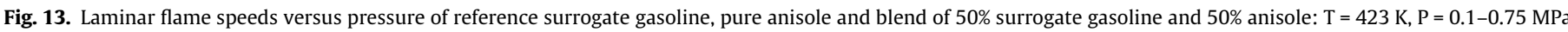
and $\varphi=0.75$; the markers are the experimental data and the lines are the fits.

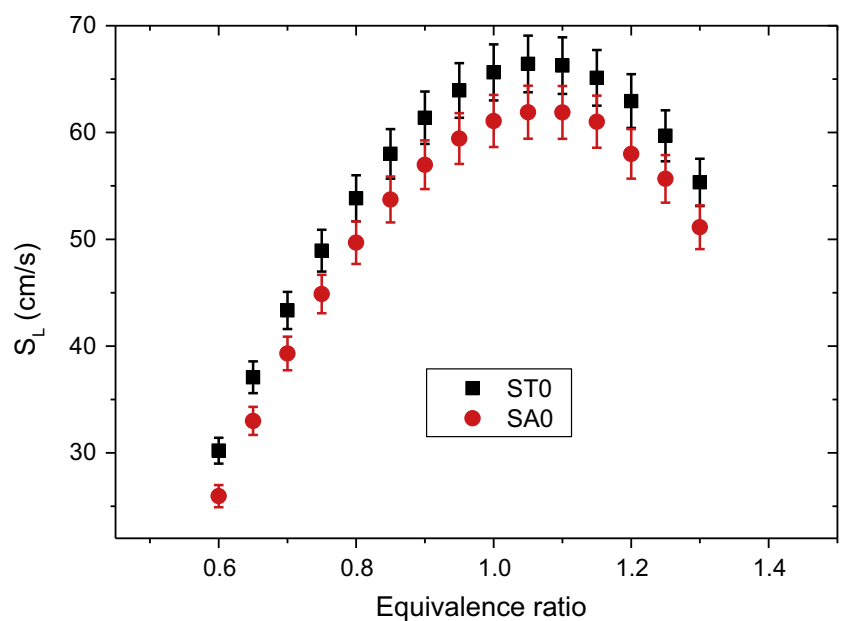

Fig. 14. Comparison of the laminar flame speeds of the SAO/air and STO/air mixtures at $\mathrm{T}=423 \mathrm{~K}, \mathrm{P}=0.1 \mathrm{MPa}$ and $\varphi=0.6-1.3$.

ture. Comparison of these exponent parameters shows that even though the existence of a dependence of the pressure parameter with the amount of oxygenates, the effects is meanwhile limited. The larger the concentration of anisole, the larger the pressure dependence on laminar flame speed will be. Therefore, SA100 surrogate will present a larger sensitivity to the pressure than the observed for the SA0 surrogate.

\subsubsection{Mixture of STO}

A final experiment was to study the respective influence of toluene and anisole when added to the SAO surrogate. Toluene is an essential aromatic component found in gasoline and surrogate fuels seeing it plays an important role in suppressing autoignition and reduce the tendency of engine knock with a higher RON number compared to typical n-alkanes $[47,48]$. Anisole has the similar RON value ( 118 for toluene and 119 for anisole) indicating the same advantages with those of toluene presents in gasoline fuels. The laminar flame speeds of SA0 and ST0, at T=423 K are shown in Fig. 14. The substitution of toluene by anisole into the

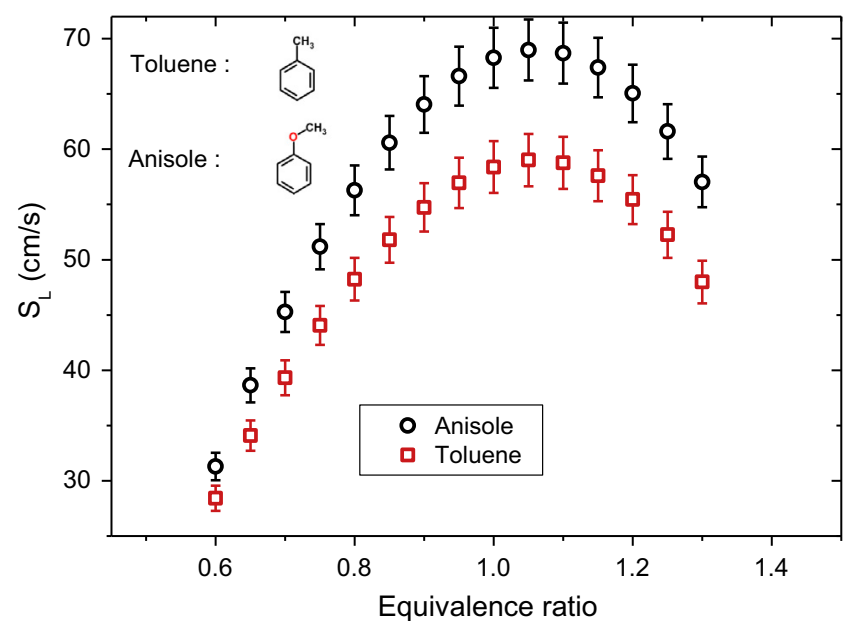

Fig. 15. Comparison of the laminar flame speeds of anisole and toluene at $\mathrm{T}=423 \mathrm{~K}$ $\mathrm{P}=0.1 \mathrm{MPa}$ and $\varphi=0.6-1.3$.

same mixture (isooctane, hexane, cyclohexane, 2,3 dimethyl-2butene) systematically exhibits faster laminar flame speeds. The laminar flame speed of ST0 is found to have a peak value of approximately $67 \mathrm{~cm} / \mathrm{s}$ at $\varphi=1.1$, significantly higher than that of SA0, around $60 \mathrm{~cm} / \mathrm{s}$. The increase of the laminar flame speed with addition of anisole (or similar oxygenates) in significant contents would lead to an increase in fuel efficiency and engine performance. This result reflects the combustion properties of anisole which alone displays larger values of the laminar flame speeds compared to the toluene. As proof, Fig. 15 shows the comparison of the laminar flame speeds of anisole with those of toluene. It shows that toluene has slower flame speeds (up to $10 \mathrm{~cm} / \mathrm{s}$ ) compared to anisole over the whole equivalence ratio range investigated. From these results, it is understandable that the evolution of the laminar flame speeds of each compound follows the same tendency than the ones observed when these molecules are included into the SAO and STO surrogates. As the other oxygenates investigated in the present study show similar behaviors to anisole (high RON and laminar flame speeds), foreseeable conclusion can 
be given that in a view of laminar flame speed these oxygenates that belong to the methyl aryl ethers or ethyl ester chemical families offers good potentialities to improve the combustion efficiency of gasoline engine while reducing auto-ignition and knocking effects.

\section{Conclusion}

Laminar flame speed measurements of oxygenated compound present in pyrolysis oil dedicated to gasoline were addressed. Anisole, 4-methylanisole and ethylvalerate were chosen as oxygenated compounds to study the effect of the addition of oxygenates to gasoline. Laminar flame speed of pure oxygenate fuels were measured in a wide range of operating conditions and results were discussed. Then, a five-component surrogate gasoline was firstly proposed and its laminar flame speed was compared with those of surrogate and commercial gasoline referenced in literature. It is found that the surrogate gasoline proposed in the current study has the ability to reproduce the laminar flame speed of commercial gasoline. Finally, the aforementioned oxygenate (anisole) was added to the surrogate gasoline to study the effects of oxygenates on laminar flame speed acting on gasoline fuels. It is found that the laminar flame speed generally increases with the addition of oxygenates. However, when the percentage of oxygenates is less than $10 \%$, the laminar flame speed is relatively insensitive. It is also observed that the use of oxygenates at higher concentration could potentially improve the combustion efficiency of engines in regards to their capacities to increase laminar flame speeds and to have an elevated RON.

\section{References}

[1] Azadi P, Inderwildi OR, Farnood R, King DA. Liquid fuels, hydrogen and chemicals from lignin: a critical review. Renewable Sustainable Energy Rev 2013;21:506-23.

[2] Talmadge MS, Baldwin RM, Biddy MJ, McCormick RL, Beckham GT, Ferguson $\mathrm{GA}$, et al. A perspective on oxygenated species in the refinery integration of pyrolysis oil. Green Chem 2014;16:407-53.

[3] Dinesh Mohan J, Pittman Charles U, Steele PH. Pyrolysis of wood/biomass for bio-oil: a critical review. Energy Fuels 2006;20:848-89.

[4] Popov A, Kondratieva E, Goupil JM, Mariey L, Bazin P, Gilson J-P, et al. Bio-oils Hydrodeoxygenation: adsorption of Phenolic Molecules on Oxidic Catalyst Supports. J Phys Chem C 2010;114(37):15661-70.

[5] Christensen ED, Chupka GM, Luecke J, Smurthwaite T, Alleman TL, Iisa K, et al. Analysis of oxygenated compounds in hydrotreated biomass fast pyrolysis oil distillate fractions. Energy Fuels 2011;25(11):5462-71.

[6] McCormick RL, Ratcliff MA, Christensen E, Fouts L, Luecke J, Chupka GM, et al. Properties of oxygenates found in upgraded biomass pyrolysis oil as components of spark and compression ignition engine fuels. Energy Fuels 2015;29(4):2453-61.

[7] Arbogast S, Bellman D, Paynter J, Wykowski J. Advanced bio-fuels from pyrolysis oil: the impact of economies of scale and use of existing logistic and processing capabilities. Fuel Process Technol 2012;104:121-7.

[8] Beeckmann J, Cai L, Pitsch H. Experimental investigation of the laminar burning velocities of methanol, ethanol, n-propanol, and n-butanol at high pressure. Fuel 2014;117(Part A):340-50.

[9] Wang Z, Weng W, He Y, Li Z, Cen K. Effect of $\mathrm{H} 2 / \mathrm{CO}$ ratio and $\mathrm{N}_{2} / \mathrm{CO}_{2}$ dilution rate on laminar burning velocity of syngas investigated by direct measurement and simulation. Fuel 2015;141:285-92.

[10] Varea E, Modica V, Renou B, Boukhalfa AM. Pressure effects on laminar burning velocities and markstein lengths for isooctane/ethanol/air mixtures. Proc Combust Inst 2013;34(1):735-44

[11] Nilsson E, de Goey L, Konnov A. Laminar burning velocities of acetone in air at room and elevated temperatures. Fuel 2013;105:496-502.

[12] Konnov A, Meuwissen R, de Goey L. The temperature dependence of the laminar burning velocity of ethanol flames. Proc Combust Inst 2011;33 (1):1011-9.

[13] Egolfopoulos F, Du D, Law C. A study on ethanol oxidation kinetics in laminar premixed flames, flow reactors, and shock tubes. Symp (Int) Combust 1992;24 (1):833-41.

[14] Dirrenberger P, Glaude P, Bounaceur R, Gall HL, da Cruz AP, Konnov A, et al. Laminar burning velocity of gasolines with addition of ethanol. Fue 2014;115:162-9.
[15] Liao S, Jiang D, Huang Z, Zeng K, Cheng Q. Determination of the laminar burning velocities for mixtures of ethanol and air at elevated temperatures. Appl Therm Eng 2007;27(23):374-80.

[16] Song KH, Nag P, Litzinger TA, Haworth DC. Effects of oxygenated additives on aromatic species in fuel-rich, premixed ethane combustion: a modeling study. Combust Flame 2003;135(3):341-9.

[17] Agarwal AK. Biofuels (alcohols and biodiesel) applications as fuels for internal combustion engines. Prog Energy Combust Sci 2007;33(3):233-71.

[18] Bradley D, Lawes M, Mansour M. Explosion bomb measurements of ethanol/air laminar gaseous flame characteristics at pressures up to $1.4 \mathrm{MPa}$. Combust Flame 2009;156(7):1462-70.

[19] Broustail G, Seers P, Halter F, Morac G, Mounaim-Rousselle C. Experimental determination of laminar burning velocity for butanol and ethanol iso-octane blends. Fuel 2011;90(1):1-6.

[20] Wang C, Xu H, Daniel R, Ghafourian A, Martin J. Combustion characteristics and emissions of 2-methylfuran compared to 2,5-dimethylfuran, gasoline and ethanol in a DISI engine. Fuel 2013;103:200-11.

[21] Wu X, Huang Z, Wang X, Jin C, Tang C, Wei L, et al. Laminar burning velocities and flame instabilities of 2,5-dimethylfuranâ€"air mixtures at elevated pressures. Combust Flame 2011;158(3):539-46.

[22] Ma X, Jiang C, Xu H, Ding H, Shuai S. Laminar burning characteristics of 2methylfuran and isooctane blend fuels. Fuel 2014;116:281-91.

[23] Dayma G, Halter F, Foucher F, Togb C, Mounaim-Rousselle C, Dagaut P. Experimental and detailed kinetic modeling study of ethyl pentanoate (ethyl valerate) oxidation in a jet stirred reactor and laminar burning velocities in a spherical combustion chamber. Energy Fuels 2012;26(8):4735-48.

[24] Sileghem L, Alekseev V, Vancoillie J, Geem KV, Nilsson E, Verhelst S, et al. Laminar burning velocity of gasoline and the gasoline surrogate components iso-octane, n-heptane and toluene. Fuel 2013;112:355-65.

[25] Mannaa O, Mansour MS, Roberts WL, Chung SH. Laminar burning velocities at elevated pressures for gasoline and gasoline surrogates associated with $\{\mathrm{RON}\}$. Combust Flame 2015;162(6):2311-21.

[26] Zhong B-J, Zheng D. A chemical mechanism for ignition and oxidation of multicomponent gasoline surrogate fuels. Fuel 2014;128:458-66.

[27] Heghes C, Morgan N, Riedel U, Warnatz J, Quiceno R, Cracknell RF, Development and validation of a gasoline surrogate fuel kinetic mechanism. SAE Technical Paper 2009-01-0934, 2009.

[28] Battin-Leclerc F. Detailed chemical kinetic models for the low-temperature combustion of hydrocarbons with application to gasoline and diesel fuel surrogates. Prog Energy Combust Sci 2008:34(4):440-98.

[29] Marshall S, Taylor S, Stone C, Davies T, Cracknell R. Laminar burning velocity measurements of liquid fuels at elevated pressures and temperatures with combustion residuals. Combust Flame 2011;158(10):1920-32.

[30] Wu Y, Modica V, Rossow B, Grisch F. Effects of pressure and preheating temperature on the laminar flame speed of methane/air and acetone/air mixtures. Fuel 2016;185:577-88.

[31] Bouvet N, Chauveau C, H. I., Experimental studies of the fundamental flame speeds of syngas $\left(\mathrm{H}_{2} / \mathrm{CO}\right) /$ air mixture. In: Proc Combust Inst 2011:33;913-920

[32] Mazas A, Fiorina B, Lacoste D, Schuller T. Effects of water vapor addition on the laminar burning velocity of oxygen-enriched methane flames. Combust Flame 2011;158(12):2428-40.

[33] Wu Y, Wu X, Yao L, Xue Z, Wu C, Zhou H, et al. Simultaneous particle size and 3D position measurements of pulverized coal flame with digital inline holography. Fuel 2017;195:12-22.

[34] Gao X, Zhang Y, Adusumilli S, Seitzman J, Sun W, Ombrello T, et al. The effect of ozone addition on laminar flame speed. Combust Flame 2015;162 (10):3914-24.

[35] Sun S, Meng S, Zhao Y, Xu H, Guo Y, Qin Y. Experimental and theoretical studies of laminar flame speed of $\mathrm{CO} / \mathrm{H}_{2}$ in $\mathrm{O}_{2} / \mathrm{H}_{2} \mathrm{O}$ atmosphere. Int J Hydrogen Energy 2016;41(4):3272-83.

[36] Natarajan J, Lieuwen T, Seitzman J. Laminar flame speeds of $\mathrm{H}_{2} / \mathrm{CO}$ mixtures: effect of $\left\{\mathrm{CO}_{2}\right\}$ dilution, preheat temperature, and pressure. Combust Flame 2007; 151(12):104-19.

[37] Yu G, Law C, Wu C. Laminar flame speeds of hydrocarbon + air mixtures with hydrogen addition. Combust Flame 1986;63(3):339-47.

[38] Toulouzan JNL, Locquet JJ, Allano D, Savary P, Darrigo R. Abel's inversion of a cylindrical helium plasma. Production of a stigmatic spectrograph using a vidicon detector. J Opt 1981;12(6):369.

[39] Lange J-P, Price R, Ayoub P, Louis J, Petrus L, Clarke L, et al. Valeric biofuels: a platform of cellulosic transportation fuels. Angew Chem Int Ed 2010;49 (26):4479-83.

[40] M. Katshiatshia, E. Nilsson, H.J.V. Dias and A.A. Konnov, Experimental studies and kinetic modeling of Ethylvalerate: flat flame structures and laminar flame burning velocity, in: 7th European Combustion Meeting, 2015.

[41] Cai L, Pitsch H. Optimized chemical mechanism for combustion of gasoline surrogate fuels. Combust Flame 2015;162(5):1623-37.

[42] Morgan N, Smallbone A, Bhave A, Kraft M, Cracknell R, Kalghatgi G. Mapping surrogate gasoline compositions into RON/MON space. Combust Flame 2010;157(6):1122-31.

[43] Ghosh P, Hickey KJ, Jaffe SB. Development of a detailed gasoline compositionbased octane model. Ind Eng Chem Res 2006;45(1):337-45.

[44] Baloo M. Dariani BM, Akhlaghi M. AghaMirsalim M. Effects of pressure and temperature on laminar burning velocity and flame instability of iso-octane/ methane fuel blend. Fuel 2016;170:235-44. 
[45] Katoch A, Asad M, Minaev S, Kumar S. Measurement of laminar burning velocities of methanol-air mixtures at elevated temperatures. Fuel 2016;182:57-63.

[46] Metghalchi M, Keck JC. Burning velocities of mixtures of air with methanol, isooctane, and indolene at high pressure and temperature. Combust Flame $1982 ; 48: 191-210$.
[47] Ji C, Dames E, Wang H, Egolfopoulos FN. Propagation and extinction of benzene and alkylated benzene flames. Combust Flame 2012;159(3):1070-81.

[48] Ranzi E, Frassoldati A, Grana R, Cuoci A, Faravelli T, Kelley A, et al. Hierarchica and comparative kinetic modeling of laminar flame speeds of hydrocarbon and oxygenated fuels. Prog Energy Combust Sci 2012;38(4):468-501. 